\title{
Methyl donor supplementation suppresses the progression of liver lipid accumulation while modifying the plasma triacylglycerol lipidome in periparturient Holstein dairy cows
}

\author{
Y. Zang, ${ }^{1}$ S. Saed Samii, ${ }^{1}$ W. A. Myers, ${ }^{1}$ H. R. Bailey, ${ }^{1}$ A. N. Davis, ${ }^{1}$ E. Grilli, ${ }^{2}$ and J. W. McFadden ${ }^{1,3 *}$ \\ ${ }^{1}$ Division of Animal and Nutritional Sciences, West Virginia University, Morgantown 26505 \\ ${ }^{2}$ Department of Veterinary Medical Sciences, University of Bologna, Bologna, Italy 40064 \\ ${ }^{3}$ Department of Animal Science, Cornell University, Ithaca 14853
}

\section{ABSTRACT}

Co-supplementation of methyl donors may lower hepatic lipid content in transition cows. To define the ability of methyl donor supplementation (MDS) to reduce hepatic lipid content and modify the plasma lipidome, 30 multiparous Holstein cows $(2.04 \pm 0.69$ lactations; $689 \pm 58 \mathrm{~kg}$ of body weight; $3.48 \pm 0.10$ units of body condition score) were fed a ration with or without rumen-protected methyl donors $(22 \mathrm{~g} / \mathrm{d}$ of Met, $10 \mathrm{~g} / \mathrm{d}$ of choline chloride, $3 \mathrm{~g} / \mathrm{d}$ of betaine, 96 $\mathrm{mg} / \mathrm{d}$ of riboflavin, and $1.4 \mathrm{mg} / \mathrm{d}$ of vitamin $\mathrm{B}_{12}$ ) from $\mathrm{d}-28$ before expected calving through d 14 postpartum. Cows were randomly enrolled based on predefined selection criteria (body condition score and parity). Base diets without MDS were formulated for gestation $(15.4 \%$ crude protein with a predicted Lys-to-Met ratio of $3.25 ; 1.44$ Mcal of net energy for lactation/ $\mathrm{kg}$ of dry matter) and lactation $(16.6 \%$ crude protein with a predicted Lys-to-Met ratio of 3.36; 1.64 Mcal of net energy for lactation $/ \mathrm{kg}$ of dry matter). Blood sampling occurred from $\mathrm{d}-28$ relative to expected calving through d 14 postpartum. Liver tissue was biopsied at $\mathrm{d}-28$ relative to expected calving and on $\mathrm{d} 5$ and 14 postpartum. In addition to routine analyses, serum AA concentrations on d 10 and 12 were quantified using mass spectrometry. Plasma triacylglycerol (TAG) and cholesteryl esters (CE) were qualitatively measured using time-of-flight mass spectrometry. Data were analyzed using a mixed model with repeated measures. Dry matter intake and milk yield were not modified by MDS. The transition from $\mathrm{d}-28$ relative to expected parturition to d 14 postpartum was characterized by increased plasma fatty acid (0.15 to $0.71 \mathrm{mmol} / \mathrm{L})$ and $\beta$-hydroxybutyrate $(0.34$ to $0.43 \mathrm{mmol} / \mathrm{L}$ ) levels and liver lipid content (3.91 to 9.16\%). Methyl donor

Received March 9, 2018.

Accepted September 28, 2018.

*Corresponding author: jwm43@cornell.edu supplementation increased the serum Met level by $26 \%$ and decreased the serum Lys-to-Met ratio by $21 \%$ on d 10 and 12, respectively. Moreover, the increase in hepatic lipid content from d 5 through 14 postpartum was suppressed with MDS relative to control (3.57 vs. $-0.29 \%$ ). Dietary MDS modified the TAG and CE lipidome. For example, MDS increased plasma TAG 46:3 (carbon number:double bond) by $116 \%$ relative to control cows on d 5 postpartum. Moreover, MDS tended to increase plasma CE 34:6. In contrast, MDS lowered plasma TAG $54: 8$ by $39 \%$ relative to control cows on d 5 postpartum. We concluded that in the absence of gains in dry matter intake and milk and milk protein yields, dietary MDS slows the progression of hepatic lipid accumulation and modifies the plasma TAG lipidome in transition cows.

Key words: methyl donor, peripartal cow, triacylglycerol

\section{INTRODUCTION}

Dairy cows mobilize adipose triacylglycerol (TAG) to increase circulating nonesterified fatty acids (FA) and glycerol to support the energy demands of late gestation and early lactation. Increased plasma nonesterified FA are used for hepatic TAG esterification and ketogenesis. Unfortunately, enhanced TAG formation and reduced TAG export via very low density lipoproteins (VLDL) promote steatosis (Emery et al., 1992). The accumulation of hepatic TAG and elevated plasma FA and ketones (e.g., BHB) are reflective of poor metabolic health. Although the mechanisms of limited VLDL secretion in cows are not completely characterized, the decreased hepatic supply of methyl donors and limited synthesis of phosphatidylcholine (PC) may be responsible (Yao and Vance, 1988). Specifically, the rumen degradation of methyl donors such as Met, choline, and betaine may limit PC synthesis by decreasing flux through the phosphatidylethanolamine $N$-methyltransferase pathway (Preynat et al., 2010). 
Because PC is an essential component of the VLDL monolayer (Vermeulen et al., 1997), limitations in PC synthesis may suppress VLDL assembly (Yao and Vance, 1988).

Liver lipid infiltration develops in peripartal dairy cows fed diets containing inadequate or adequate Met (Zhou et al., 2016b; Zenobi et al., 2018). A potential approach to mitigate fatty liver is dietary methyl donor supplementation (MDS). Choline and Met are methyl donors that have received attention. Supplementation of rumen-protected (RP) choline chloride (11.7 to 14.4 $\mathrm{g} / \mathrm{d}$ of choline ion) has been shown to increase serum total TAG (Guretzky et al., 2006) and decrease liver total TAG concentrations (Zom et al., 2011); however, these findings were not observed by others (Zahra et al., 2006; Zhou et al., 2016b; Zenobi et al., 2018). The abilities of RP-Met (Met at 0.07 to $0.10 \%$ ration DM) to mitigate hepatic lipid accrual are also inconsistent. Dietary Met or Met hydroxy analog supplementation elevated serum TAG concentrations and lowered liver TAG (Huber et al., 1984; Osorio et al., 2013); however, changes in plasma VLDL or liver TAG were not observed in other studies (Osorio et al., 2013; Zhou et al., 2016b; Batistel et al., 2017). Variations in outcomes may be due to a variety of factors, including methyl donor type, feeding level, bioavailability, and study design. Moreover, the dietary metabolizable Met level and metabolic status of the animal (e.g., hepatic PC deficiency or sufficiency) may dictate methyl donor efficacy. These uncertainties are complicated by the emergence of an alternative RP-methyl donor, betaine, as a means to activate transmethylation and support hepatic TAG secretion (Davidson et al., 2008). Considering the potential benefits of individual MDS, we postulated that co-supplementation of choline, Met, betaine, riboflavin, and vitamin $\mathrm{B}_{12}$, which are all involved in one-carbon metabolism, may synergistically enhance hepatic lipid disposal.

The refinement of MDS feeding strategies to alleviate hepatic steatosis requires insight into TAG metabolism. Lipidomics may be employed to avoid the generalization of complex lipids. For instance, the hepatic levels of TAG species having a low degree of unsaturation ( $<4$ double bonds) are higher in obese rodents with fatty liver relative to control animals with healthy liver (Nam et al., 2015). Moreover, the development of nonalcoholic fatty liver disease in humans is associated with decreased plasma levels of TAG containing very long-chain FA, including lignoceric (24:0), nervonic (24:1n-9), and docosadienoic (22:2n-6) acids (Puri et al., 2009). Considering that MDS may modulate hepatic and circulating TAG (Pinotti et al., 2002), the effects of MDS on these plasma TAG and others within the context of liver lipid infiltration deserves consider- ation. Therefore, we tested the hypothesis that dietary MDS would lower hepatic lipid content and modify the plasma TAG lipidome in transition cows fed diets containing metabolizable Met in excess of predicted requirements.

\section{MATERIALS AND METHODS}

\section{Experimental Design}

Experimental procedures were approved by the Institutional Animal Care and Use Committee at West Virginia University (Morgantown). Thirty multiparous (second and third lactation), nonlactating pregnant Holstein cows were randomly enrolled in a study completed at DoVan Farms, West Virginia University Agricultural Research and Education Partner, and a 700-Holstein cow commercial dairy farm (Berlin, PA). Selection criteria included cows with a BCS between 3.0 and 3.75 (3.48 \pm 0.10 units; Wildman et al., 1982) in second or third lactation $(2.04 \pm 0.69$ lactations). Previous milk yield for all cows was $10,838 \pm 2,434 \mathrm{~kg}$ of 305 -d mature-equivalent yield. Cows were individually housed in straw-bedded pens and fed diets ad libitum in the absence (control) or presence of supplemental methyl donors $(22 \mathrm{~g} / \mathrm{d}$ of Met, $10 \mathrm{~g} / \mathrm{d}$ of choline chloride, 3 $\mathrm{g} / \mathrm{d}$ of betaine, $96 \mathrm{mg} / \mathrm{d}$ of riboflavin, and $1.4 \mathrm{mg} / \mathrm{d}$ of vitamin $\mathrm{B}_{12}$; MecoVit, Vetagro S.p.A., Reggio Emilia, Italy) in addition to $65 \mathrm{~g} / \mathrm{d}$ of vegetable-derived TAG encapsulate (Vetagro S.p.A.). Similar feeding levels of Met and choline chloride have previously improved metabolic health in transition dairy cows (Zhou et al., 2016b; Batistel et al., 2017). The prepartum and postpartum unsupplemented basal diets were predicted to provide metabolizable Met at 199 and $115 \%$ of estimated requirements and Lys-to-Met ratios of 3.25 and 3.36, respectively, which were determined by the Cornell Net Carbohydrate and Protein System (Version 6.1, Cornell University, Ithaca, NY). Moreover, the estimated duodenal flow of metabolizable Met was 32.0 and $66.0 \mathrm{~g} / \mathrm{d}$ for the dry cow and lactation base rations in the absence of RP MDS, respectively. Diets were offered as TMR twice daily (0900 and $1800 \mathrm{~h}$ ) and daily orts were collected before the morning feeding and maintained between 5 and 10\%. Supplemental methyl donors and TAG encapsulate were top-dressed daily. Cows were milked twice daily from 1 through 14 DIM and milk yields were recorded daily. Cows were weighed to record BW and BCS was determined by 3 trained investigators weekly.

Dietary forages and concentrates were sampled weekly and composited monthly. Milk samples were collected at each milking on d 1 through 10, and again on d 14 postpartum. Blood samples $(\sim 10 \mathrm{~mL})$ were 
collected from the coccygeal vein into Vacutainer tubes (Becton Dickinson and Co., Franklin Lakes, NJ) containing EDTA or clot activator before morning feeding on $\mathrm{d}-28$ (baseline measurements before treatment), -21 , and -14 , daily from $\mathrm{d}-7$ through 7 , and on $\mathrm{d} 10$, 12 , and 14, relative to expected or actual calving. Blood samples were also collected into serum Vacutainer tubes containing clot activator at 3,6 , and $9 \mathrm{~h}$ after morning feeding on d 10 and 12 postpartum. For plasma collection, tubes with EDTA were placed on ice for $30 \mathrm{~min}$ until centrifugation at $3,400 \times g$ for $10 \mathrm{~min}$ at $4^{\circ} \mathrm{C}$. For serum collection, tubes were allowed to clot for $30 \mathrm{~min}$ at room temperature before centrifugation at 3,400 $\times g$ for $10 \mathrm{~min}$ at $4^{\circ} \mathrm{C}$. Liver biopsies were conducted on $\mathrm{d}$ -28 (baseline), 5, and 14 relative to expected or actual calving, as described (Jorritsma et al., 2001). In brief, the 11th intercostal space was clipped, sanitized with iodine scrub, and anesthetized using $2 \%$ lidocaine $\mathrm{HCl}$ (Vedco Inc., Saint Joseph, MO). A fabricated trocar was inserted through a small incision to collect approximately $1 \mathrm{~g}$ of liver tissue. Separated plasma and serum and biopsied liver tissue were snap-frozen in liquid nitrogen and then stored at $-80^{\circ} \mathrm{C}$ until further analysis.

\section{Experimental Analyses}

Daily DM content of TMR was determined by drying feed samples at $60^{\circ} \mathrm{C}$ until a static weight was observed. Dry matter intake was calculated by using daily feed intake and DM content of TMR. Feed samples were analyzed by a commercial laboratory for nutrient composition using wet chemistry (Cumberland Valley Analytical, Cumberland, MD). Neutral detergent fiber was measured with heat-stable $\alpha$-amylase and sodium sulfite (Van Soest et al., 1991), and CP and starch were analyzed following established procedures (AOAC International, 2000, method 990.03; Hall, 2009). Milk samples were used to determine content of fat, protein and lactose by mid-infrared procedures (Dairy One, Hagerstown, MD).

Serum AA quantification was performed using the EZ:faast GC-MS Free (Physiological) AA Analysis Kit (KG0-7166; Phenomenex, Torrence, CA) using norvaline as an internal standard for normalization. Extracted serum AA were quantified using a Thermo Scientific TRACE 1310 series gas chromatograph coupled to a TSQ8000 tandem mass spectrometer (GC-MS/MS) equipped with an AI/AS 1310 autosampler (Thermo Fisher Scientific, Waltham, MA). Samples were derivatized and analyzed following the manufacturer's protocol as described by Badawy et al. (2008). Amino acids were measured by selected reaction monitoring using XCalibur software (Thermo Fisher Scientific). Serum samples were sent to a commercial laboratory for total protein and albumin analysis by indirect potentiometry (Animal Health Diagnostic Center; Cornell University, Ithaca, NY).

Plasma samples were analyzed for nonesterified FA, BHB, glucose, insulin, total TAG, and total and free cholesterol. Plasma nonesterified FA, BHB, glucose, total TAG, and total and free cholesterol concentrations were measured by enzymatic methods using commercial kits (\#999-34691, \#995-34791, \#991-34891, \#993-35191, HR Series nonesterified FA-HR (2); \#417-73501, \#413-73601, Autokit 3-HB; \#997-03001, Autokit Glucose; \#994-02891, \#990-02991, L-Type TAG M; \#439-17501, Cholesterol E; and \#435-35801, Free Cholesterol E, respectively; Wako Chemicals USA Inc., Richmond, VA). Plasma insulin concentration was measured by ELISA using a commercial kit (\#10-1201-01, Mercodia Bovine Insulin; Mercodia AB, Uppsala, Sweden). Liver samples were used to determine the percentage of total lipid in liver as previously described by Starke et al. (2010). Of importance to classifying the severity of liver lipid accumulation, total lipid (up to $450 \mathrm{mg} / \mathrm{g}$ of wet liver) was highly related to TAG (2-slope broken-line model; Starke et al., 2010).

For lipidomics, plasma samples were extracted using a modified Bligh and Dyer (1959) procedure to obtain a crude lipid fraction. In brief, $60 \mu \mathrm{L}$ of plasma was gently mixed in a glass vial with $940 \mathrm{~mL}$ of distilled deionized $\mathrm{H}_{2} \mathrm{O}$ and $2.9 \mathrm{~mL}$ of methanol/dichloromethane $(2: 0.9, \mathrm{vol} / \mathrm{vol})$ containing 1,3(d5)-dihexadecanoyl2-octadecanoyl-glycerol (D-5 TAG 16:0/18:0/16:0, 0.5 $\mathrm{ng} / \mathrm{mL}$ ) and cholesteryl-d7 palmitate (cholesteryl-d7 ester 16:0, $30 \mathrm{ng} / \mathrm{mL}$ ), purchased from Avanti Polar Lipids Inc. (Alabaster, AL). To obtain a biphasic mixture, an additional $1 \mathrm{~mL}$ of distilled deionized $\mathrm{H}_{2} \mathrm{O}$ and $0.9 \mathrm{~mL}$ of dichloromethane was added and vortexed. The resultant mixture was incubated on ice for $30 \mathrm{~min}$ and centrifuged $\left(10 \mathrm{~min}, 3,000 \times g, 4^{\circ} \mathrm{C}\right)$ to separate the organic and aqueous phases. The organic phase was removed and stored at $-20^{\circ} \mathrm{C}$. Just before analysis, $1 \mathrm{~mL}$ of the organic layer was dried using a nitrogen evaporator (Organomation Associates Inc., Berlin, $\mathrm{MA}$ ) and resuspended in $250 \mu \mathrm{L}$ of running solvent [dichloromethane:methanol (1:1) containing $5 \mathrm{~m} M$ ammonium acetate], and $5 \mathrm{mg} / \mathrm{mL}$ of ceramide C17:0 used to track instrument performance. All solvents used were HPLC-grade.

Lipid analysis was conducted by $\mathrm{MS} / \mathrm{MS}^{\mathrm{ALL}}$ on a TripleTOF 5600 (AB Sciex, Redwood City, CA) timeof-flight mass spectrometer (TOF MS). Samples (50 $\mu \mathrm{L}$ injection volume) were infused by HPLC at a constant flow rate of $5 \mu \mathrm{L} / \mathrm{min}$ using a LC-20AD pump and SIL-20AC XR autosampler (Shimazu, Canby, OR). Source parameters were ion source gases at 15 (GSI) and 20 psi (GS2), curtain gas at $30 \mathrm{psi}$, temperature 
at $150^{\circ} \mathrm{C}$, positive ion spray voltage at $5,500 \mathrm{~V}$, declustering potential at $80 \mathrm{~V}$, and collision energy at $10 \mathrm{~V}$. Each sample was run in duplicate in positive ion mode. An initial TOF MS scan provided an overview of the total lipid content at an accumulation time of $5 \mathrm{~s}$. Precursor ions were selected by sequential 1 -Da mass steps from 200 to $1,200 \mathrm{~m} / z$, and the analytes in each 1-Da step were introduced into the collision chamber and fragments identified by TOF MS with a scan range of 100 to $1,500 \mathrm{~m} / z$ and accumulation time of $450 \mathrm{~ms}$. The TOF MS and MS/MS ${ }^{\text {ALL }}$ data obtained were postaligned to internal standards using Analyst TF 1.7 (AB Sciex).

Lipid identifications were validated using a pooled sample that was extracted and sequentially analyzed 8 times. Criteria for inclusion of lipid analytes for analysis was that MS/MS fragment peaks were present in 7 of the 8 pooled runs and coefficient of variation for peak identifications were less than $20 \%$. Peak identifications meeting these criteria were then used to develop a targeted method in LipidView (AB Sciex, Concord, ON, Canada). The targeted method was used to identify these prevalidated lipid species in experimental samples using a custom made MatLab script and MultiQuant software (version 3.0, AB Sciex, Concord). All peak intensities were corrected by their corresponding internal standard, and each sample duplicate was averaged. All lipidomic data are denoted as fold-change relative to $\mathrm{d}$ -28 (baseline).

\section{In Situ Rumen Disappearance and Intestinal Digestibility of MDS}

At Cornell University, with Institutional Animal Care and Use Committee approval, ruminal disappearance of experimental methyl donors (MecoVit, Vetagro S.p.A.) was evaluated using a standard in situ procedure with 5 ruminally cannulated late-lactation multiparous Holstein dairy cows $(175 \pm 4 \mathrm{DIM} ; 34 \pm 6 \mathrm{~kg} / \mathrm{d}$ of milk yield). Five grams of RP MDS was placed into $10 \times 20$ $\mathrm{cm}, 50-\mu \mathrm{m}$ porosity nylon bags (Ankom Technology, Macedon, NY) and incubated in the rumen of the cow for 0 (washed in cold water but not incubated in the rumen), 4, 8, 12, 16, and $20 \mathrm{~h}$. Bags were incubated in paired duplicates for each time point, inserted into the rumen in reverse order, and removed collectively after incubation. All bags were washed in cold tap water until the wash water was clear. All supplement bags were dried at $35^{\circ} \mathrm{C}$ for $24 \mathrm{~h}$. Duplicate residues were composited (2 composites/cow per time point) and finely ground for $\mathrm{N}$ measurement by block digestion and steam distillation with automatic titration (AOAC International, 2006; method 2001.11). Performed in duplicate to assess estimated intestinal digestibility, $0.5 \mathrm{~g}$ of $\mathrm{h} 16$ composite residue was transferred to a $125-\mathrm{mL}$ Erlenmeyer flask and incubated in a $3 \mathrm{M} \mathrm{HCl}$ solution for $1 \mathrm{~min}$. The residue was then incubated in $0.013 \mathrm{M} \mathrm{HCl}$ containing pepsin $(282 \mathrm{U} / \mathrm{mL})$ for $1 \mathrm{~h}$ in a shaking water bath at $39^{\circ} \mathrm{C}$. After incubation was complete, samples were neutralized to a $\mathrm{pH}$ of 5 with $2 \mathrm{M}$ $\mathrm{NaOH}$ and shaken vigorously. A $1.8 \mathrm{M} \mathrm{KH}_{2} \mathrm{PO}_{4}$ buffer solution containing bile powder $(1 \mathrm{~g} / \mathrm{L}$; Sigma-Aldrich, St. Louis, MO), trypsin (168 U/mL; Sigma-Aldrich), chymotrypsin (140 U/mL; Sigma-Aldrich), amylase (705 U/mL; Ankom Technology), and lipase (28 U/ $\mathrm{mL}$; Sigma-Aldrich) was added to samples and incubated for $24 \mathrm{~h}$ at $39^{\circ} \mathrm{C}$ in a shaking water bath. Final sample residue was collected by filtration, rinsed with cold water, dried at $35^{\circ} \mathrm{C}$ for $24 \mathrm{~h}$, and analyzed for $\mathrm{N}$.

\section{Calculations and Statistics}

Milk components were calculated using milk yield and milk composition and averaged by week. Concentrations of serum globulin and total cholesteryl esters (CE) were calculated using the following equations:

$$
\begin{gathered}
\text { Globulin = total protein - albumin; and } \\
\text { Total CE }=\text { total cholesterol }- \text { free cholesterol. }
\end{gathered}
$$

Data were analyzed using the MIXED model procedure of SAS (version 9.3; SAS Institute Inc., Cary, NC), according to the following model:

$$
\mathrm{Y}_{\mathrm{ijk}}=\mu+\mathrm{C}_{\mathrm{i}}+\mathrm{P}_{\mathrm{j}}+\mathrm{T}_{\mathrm{k}}+\left(\mathrm{P}_{\mathrm{j}} \times \mathrm{T}_{\mathrm{k}}\right)+\mathrm{e}_{\mathrm{ijk}},
$$

where $Y_{\mathrm{ijk}}=$ dependent variable, $\mu=$ overall mean, $\mathrm{C}_{\mathrm{i}}$ $=$ random effect of cow ( $\mathrm{i}=1$ to 27$), \mathrm{P}_{\mathrm{j}}=$ fixed effect of sampling time ( $\mathrm{j}=-28$ to 14 , d relative to calving), $\mathrm{T}_{\mathrm{k}}=$ fixed effect of treatment ( $\mathrm{k}=1$ to 2$), \mathrm{P}_{\mathrm{j}} \times \mathrm{T}_{\mathrm{k}}=$ interaction between sampling time and treatment, and $\mathrm{e}_{\mathrm{ijk}}=$ residual error. Three common covariance structures (variance components, first-order autoregressive, compound symmetry) for repeated measures analysis were evaluated and the structure with the smallest Akaike's information criterion coefficient was selected for analysis. Normality of the residuals was checked with normal probability and box plots and homogeneity of variances with plots of residual versus predicted values. Skewed data, including plasma nonesterified FA and lipidomic TAG and CE data, were natural log-transformed. Data were considered as outliers and removed from analysis when Studentized residuals were $>3.0$ or $<-3.0$ (typically $1-3$ per response variable). The SLICE option of SAS was used to compare 
treatments at each time point. Spearman correlation coefficients were calculated to determine relationships between production performance, lipidomic TAG and $\mathrm{CE}$, and plasma metabolites. All results are expressed as least squares means and their standard error. Significance was declared at $P \leq 0.05$ and trends at 0.05 $<P \leq 0.15$.

\section{RESULTS}

Disappearance of $\mathrm{N}$ from RP MDS in the rumen of lactating dairy cows was $23,35,40,48$, and $51 \%$ after $4,8,12,16$, and $20 \mathrm{~h}$ of ruminal incubation, and intestinal digestibility following a 16 -h rumen incubation was estimated at $75 \%$. In our evaluation of MDS in periparturient dairy cows, our data represents 27 dairy cows (13 control vs. $14 \mathrm{MDS}$ ) that did not receive clinical intervention because of the development of a metabolic disease. Within the context of previous work (Bobe et al., 2004a,b; Starke et al., 2010), 13 cows (8 control vs. $5 \mathrm{MDS}$ ) developed moderate to severe fatty liver disease by $\mathrm{d} 14$. Three cows were removed from the statistical analysis due to the occurrence of mastitis, retained placenta, and dystocia, respectively. Cows were fed gestation and lactation diets that were composed of corn silage, grass haylage, grass hay, and concentrates (Table 1). Actual prepartum day of sampling as presented was $-27 \pm 1.47(-31$ to -25$),-21 \pm 1.83(-24$ to -18$),-13 \pm 1.69(-17$ to -11$),-7.3 \pm 0.71$ ( -8 to $-6),-5.0 \pm 0.54(-6$ to -3$),-2.2 \pm 0.57(-4$ to -2$)$, and $-1.0 \pm 0(-1$ to -1$)$ before parturition.

\section{Performance Outcomes}

Dry matter intake was $12.6 \pm 0.64$ and $16.2 \pm 0.65$ $\mathrm{kg} / \mathrm{d}$ during the prepartum $(\mathrm{d}-28$ through -1$)$ and postpartum periods (d 1 through 14 ), respectively, and MDS did not modify DMI (Figure 1). Although BW and BCS were not modified by MDS, cows lost $84 \mathrm{~kg}$ of BW and 0.6 BCS units for the duration of the study $(P<0.01$; Supplemental Figure S1, https://doi.org/10 $.3168 /$ jds.2018-14727). Milk yield and milk component yield and content were not altered by MDS (Table 2).

\section{Metabolic Status}

The ability of dietary MDS to modify serum AA levels was determined (Table 3; Supplemental Table S1, https://doi.org/10.3168/jds.2018-14727). Although the majority of serum AA were not modified by MDS, cows supplemented with methyl donors had higher serum Met concentrations relative to unsupplemented control cows. Specifically, MDS increased serum Met on d 10 and $12(P<0.05)$. The Met response lowered the
Table 1. Ingredients and nutrient composition of experimental base without methyl donor supplementation (rumen-protected methionine, choline and betaine)

\begin{tabular}{|c|c|c|}
\hline \multirow[b]{2}{*}{ Item } & \multicolumn{2}{|c|}{ Diet } \\
\hline & Gestation & Lactation \\
\hline \multicolumn{3}{|l|}{ Ingredient, $\%$ of DM } \\
\hline Corn silage & 35.9 & 43.1 \\
\hline Grass haylage & 27.3 & 6.41 \\
\hline Grass hay & 14.7 & 3.13 \\
\hline Concentrate mix $\mathrm{A}^{1}$ & - & 16.1 \\
\hline Ground corn & - & 15.7 \\
\hline Concentrate mix $\mathrm{B}^{2}$ & 14.3 & - \\
\hline Soybean meal & 7.82 & 6.14 \\
\hline Cottonseed & - & 4.47 \\
\hline Concentrate mix $\mathrm{C}^{3}$ & - & 4.31 \\
\hline Fat supplement ${ }^{4}$ & - & 0.50 \\
\hline Rumensin $^{5}$ & - & 0.10 \\
\hline \multicolumn{3}{|l|}{ Nutrient composition } \\
\hline DM, $\%$ & 45.7 & 49.1 \\
\hline $\mathrm{CP}, \%$ of DM & 15.4 & 16.6 \\
\hline NDF, $\%$ of DM & 47.7 & 35.4 \\
\hline $\mathrm{ADF}, \%$ of $\mathrm{DM}$ & 29.7 & 21.7 \\
\hline NFC, $\%$ of DM & 27.5 & 39.0 \\
\hline Ash, $\%$ of DM & 8.82 & 7.24 \\
\hline $\mathrm{NE}_{\mathrm{L}}, \mathrm{Mcal} / \mathrm{kg}$ of $\mathrm{DM}$ & 1.44 & 1.64 \\
\hline
\end{tabular}

${ }^{1}$ Mix contained $28.0 \%$ citrus pulp, $30.3 \%$ soybean meal $47.5 \%, 18.7 \%$ distillers, $9.3 \%$ soy hulls, $3.3 \%$ calcium carbonate, $3.7 \%$ sodium bicarbonate, $2.3 \%$ urea, $2.3 \%$ fat, $2.1 \%$ salt, and $0.3 \%$ biotin 640 .

${ }^{2}$ Mix contained $24.9 \%$ soybean meal $47.5 \%, 23.2 \%$ ground corn, $16.6 \%$ corn distillers grain, 12.4\% Animate (Phibro Animal Health Corp. Teaneck, NJ), $10.4 \%$ calcium carbonate, $9.1 \%$ selenium yeast, $2.5 \%$ calcium sulfate, and $<1 \%$ of each of the following: Biophos, selenium yeast, and vitamin E.

${ }^{3}$ Mix contained 43.6\% Fermenten (Arm and Hammer Nutrition, Princeton, NJ), $21.8 \%$ calcium carbonate, $13.5 \%$ soybean hulls, $7.8 \%$ 1965 mill mix 4 mintrex, $5.2 \%$ blood meal, $3.5 \%$ magnesium oxide, $2.6 \%$ Celmanax (Arm and Hammer Nutrition), and $<1 \%$ of each of the following: vitamin E, selenium $0.06 \%$, and 9273 selenium yeast 600 .

${ }^{4}$ Palmitic acid supplement contained 80\% C16:0 (Palmit 80; Global Agri-Trade, Long Beach, CA).

${ }^{5}$ Rumensin (Elanco Animal Health, Greenfield, IN) for dairy mix included at $4,890 \mathrm{mg} / \mathrm{kg}$.

Lys-to-Met ratio by 28 and $13 \%$ on d 10 and 12 postpartum, respectively $(P<0.05)$. We also observed that MDS tended to increase serum Cys concentrations $(P$ $=0.09)$. On d 10 postpartum, dietary MDS decreased serum Leu concentrations (interaction, $P<0.05$ ) and tended to lower serum Val concentrations (interaction, $P=0.08)$.

Plasma insulin, glucose, nonesterified FA, and BHB concentrations were modified during the transition period (Figure 2; $P<0.01$ ). As expected, plasma insulin decreased postpartum (Figure 2A; $P<0.01$ ). Circulating glucose increased acutely at parturition and decreased postpartum (Figure 2B; $P<0.01$ ). Plasma nonesterified FA and BHB levels increased during the transition from gestation to lactation (Figure 2C and $2 \mathrm{D}$, respectively; $P<0.01$ ). Notably, dietary MDS enhanced circulating insulin prepartum $(\mathrm{d}-21$ relative 
Table 2. Milk production responses to methyl donor supplementation (MDS) in postpartum Holstein dairy cows $^{1}$

\begin{tabular}{|c|c|c|c|c|c|c|c|c|c|}
\hline Item & \multicolumn{6}{|c|}{ Treatment $^{2}$} & & & \\
\hline Milk yield, $\mathrm{kg} / \mathrm{d}$ & 31.0 & 30.5 & 0.76 & 36.8 & 34.5 & 0.77 & 0.32 & $<0.01$ & 0.20 \\
\hline \multicolumn{10}{|l|}{ Milk solid, $\mathrm{kg} / \mathrm{d}$} \\
\hline Fat & 1.63 & 1.68 & 0.05 & 1.92 & 1.83 & 0.05 & 0.81 & $<0.01$ & 0.09 \\
\hline \multicolumn{10}{|c|}{ Milk composition, \% } \\
\hline Fat & 5.2 & 5.51 & 0.14 & 5.39 & 5.32 & 0.14 & 0.61 & 0.98 & 0.21 \\
\hline Protein & 4.22 & 4.22 & 0.07 & 3.22 & 3.29 & 0.05 & 0.65 & $<0.01$ & 0.46 \\
\hline Lactose & 5.13 & 5.21 & 0.03 & 5.39 & 5.46 & 0.03 & 0.24 & $<0.01$ & 0.69 \\
\hline
\end{tabular}

${ }^{1}$ MDS contained $22 \mathrm{~g} / \mathrm{d}$ of Met, $10 \mathrm{~g} / \mathrm{d}$ of choline chloride, $3 \mathrm{~g} / \mathrm{d}$ of betaine, $96 \mathrm{mg} / \mathrm{d}$ of riboflavin and $1.4 \mathrm{mg} / \mathrm{d}$ of vitamin $\mathrm{B}_{12}$ (MecoVit, Vetagro S.p.A., Reggio Emilia, Italy) top-dressed daily to a methionine-adequate corn silage-based TMR fed ad libitum from d -28 relative to expected calving through d 14 postpartum.

${ }^{2}$ Week 1 represents mean performance from d 1 through 7 postpartum; wk 2 denotes mean performance from d 8 through 14 postpartum.

to calving; $P<0.01)$ and tended to lower plasma nonesterified FA concentrations $(P=0.12)$. Postpartum liver lipid content was moderately elevated in all cows (Figure 3A; $P<0.01$ ) relative to prepartum. Although we did not observe an overall effect of MDS on liver lipid content (Figure 3A), MDS was able to limit the progression of liver lipid accumulation from d 5 to 14 (Figure 3B; $P<0.05$ ). Determined using colorimetry, plasma total TAG and CE concentrations were lower postpartum (Figure $4 \mathrm{~A}$ and $4 \mathrm{~B}$, respectively) but were not modified by MDS. Total and free cholesterol concentrations reached a nadir at parturition (Supplemen-

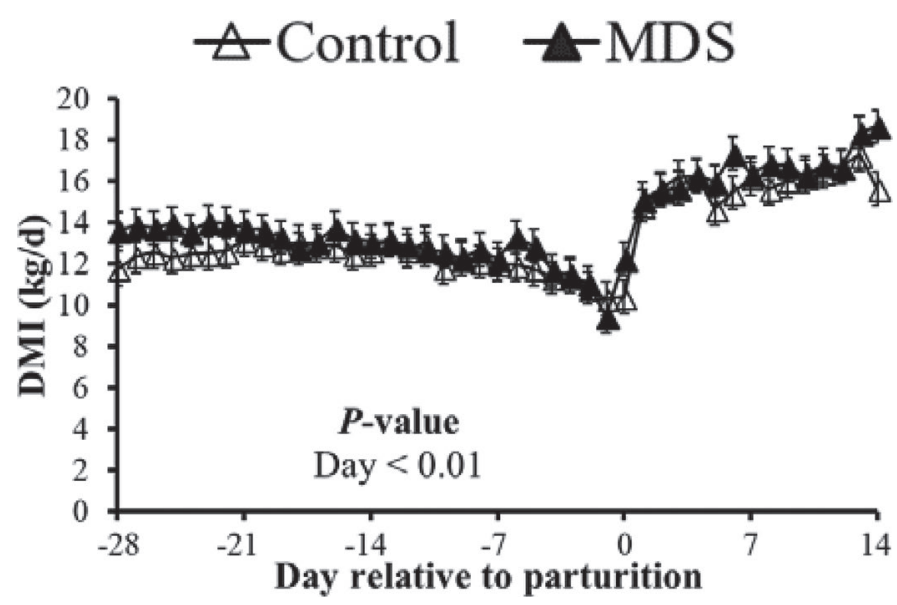

Figure 1. Dry matter intake in dairy cows ad libitum fed corn silage-based diets containing adequate Met without (control; $\mathrm{n}=13$ ) or with methyl donor supplementation (MDS; $\mathrm{n}=14$ ) during the transition period. Dietary MDS contained $22 \mathrm{~g} / \mathrm{d}$ of Met, $10 \mathrm{~g} / \mathrm{d}$ of choline chloride, $3 \mathrm{~g} / \mathrm{d}$ of betaine, $96 \mathrm{mg} / \mathrm{d}$ of riboflavin, and $1.4 \mathrm{mg} / \mathrm{d}$ of vitamin $\mathrm{B}_{12}$ (MecoVit, Vetagro S.p.A., Reggio Emilia, Italy). Data are presented as LSM \pm SEM. The $P$-values for treatment and treatment $\times$ day were greater than 0.15 . tal Figure S2, https://doi.org/10.3168/jds.2018-14727; $P<0.01)$.

Serum total protein and globulin were elevated by 9 and $20 \%$ from $d 5$ to 14 , respectively $(P<0.01$; Supplemental Figure 3A and 3B, respectively, https:/ /doi.org/10.3168/jds.2018-14727), and serum albumin concentrations were not modified (Supplemental Figure 3C, https://doi.org/10.3168/jds.2018-14727). The ratio of albumin to globulin was lowered as lactation advanced (Supplemental Figure 3D, https://doi.org/10 .3168/jds.2018-14727). Dietary MDS did not modify serum total protein, albumin, or globulin concentrations.

\section{Lipidomic Evaluation}

Our lipidomic analyses detected 53 TAG and $10 \mathrm{CE}$ neutral lipid species in bovine plasma. All TAG and CE species were modified by time $(P \leq 0.05)$. Similar to our colorimetry findings, 50 out of 53 TAG decreased (range $=-31$ to $-95 \%)$ from $\mathrm{d}-28$ to parturition $(P$ $<0.05$; Figure 5; Supplemental Table S2, https://doi .org/10.3168/jds.2018-14727). In addition, 7 out of 10 circulating $\mathrm{CE}$ species were lowest at d 1 postpartum $(P<0.01$; Figure 6; Supplemental Table S3, https:// doi.org/10.3168/jds.2018-14727). With varying efficacy, dietary MDS increased plasma TAG; for example, MDS increased plasma TAG 46:2, 46:3, 48:0, and 48:3 $(P<$ 0.05 to 0.09; Figure 4). Most notably, MDS increased plasma TAG $46: 3$ by 63 and $116 \%$ relative to control cows on $\mathrm{d}-7$ prepartum and $\mathrm{d} 5$ postpartum, respectively. In contrast, MDS lowered select TAG, including TAG 54:0, 54:1, 54:2, 54:6, 54:8, and 56:8 $(P<0.05$ to 0.09 ; Figure 5). On d 1 and 14 postpartum, plasma TAG 58:8 and 58:5 were elevated by MDS (interaction; $P<0.05$; Figure 5). Of the limited number of 
Table 3. Serum EAA response to methyl donor supplementation (MDS) in postpartum Holstein dairy cows ${ }^{1}$

\begin{tabular}{|c|c|c|c|c|c|c|c|c|c|}
\hline \multirow{2}{*}{$\begin{array}{l}\text { AA } \\
(\mu M)\end{array}$} & \multicolumn{6}{|c|}{ Treatment } & & & \\
\hline & Control & MDS & SEM & Control & MDS & SEM & Treatment & Time & Treatment $\times$ time \\
\hline \multicolumn{10}{|l|}{ EAA } \\
\hline Val & 240.7 & 210.6 & 13.2 & 220.0 & 218.3 & 13.2 & 0.36 & 0.41 & 0.08 \\
\hline Leu & 168.1 & 140.0 & 9.7 & 154.7 & 147.2 & 9.7 & 0.17 & 0.53 & 0.04 \\
\hline Met & 11.1 & 13.0 & 0.9 & 8.6 & 11.6 & 1.0 & 0.04 & 0.02 & 0.48 \\
\hline Phe & 54.1 & 48.9 & 2.1 & 51.9 & 51.8 & 2.1 & 0.34 & 0.82 & 0.10 \\
\hline Lys & 92.7 & 82.6 & 4.9 & 87.7 & 85.0 & 4.9 & 0.28 & 0.74 & 0.34 \\
\hline His & 53.7 & 54.0 & 2.6 & 51.7 & 54.4 & 2.6 & 0.66 & 0.65 & 0.52 \\
\hline $\operatorname{Trp}$ & 30.4 & 27.9 & 1.7 & 29.3 & 29.7 & 1.7 & 0.61 & 0.78 & 0.20 \\
\hline Lys:Met & 9.5 & 6.8 & 0.9 & 9.8 & 8.5 & 0.9 & 0.04 & 0.23 & 0.42 \\
\hline
\end{tabular}

${ }^{1}$ MDS contained $22 \mathrm{~g} / \mathrm{d}$ of Met, $10 \mathrm{~g} / \mathrm{d}$ of choline chloride, $3 \mathrm{~g} / \mathrm{d}$ of betaine, $96 \mathrm{mg} / \mathrm{d}$ of riboflavin, and $1.4 \mathrm{mg} / \mathrm{d}$ of vitamin $\mathrm{B}_{12}(\mathrm{MecoVit}$ Vetagro S.p.A., Reggio Emilia, Italy) top-dressed daily to a corn silage-based TMR fed ad libitum from d -28 relative expected calving through d 14 postpartum.

CE profiled, MDS selectively increased plasma CE 34:6 $(P=0.06 ;$ Figure 6$)$. Although nonesterified plasma FA, glucose, and BHB were either weakly correlated $(r<0.20)$ or not correlated with milk production data (not shown), we observed many weak to moderate correlations $(r=0.20$ to $0.51 ; P<0.05)$ between many

\section{$\triangle$ Control $\triangle$ MDS}
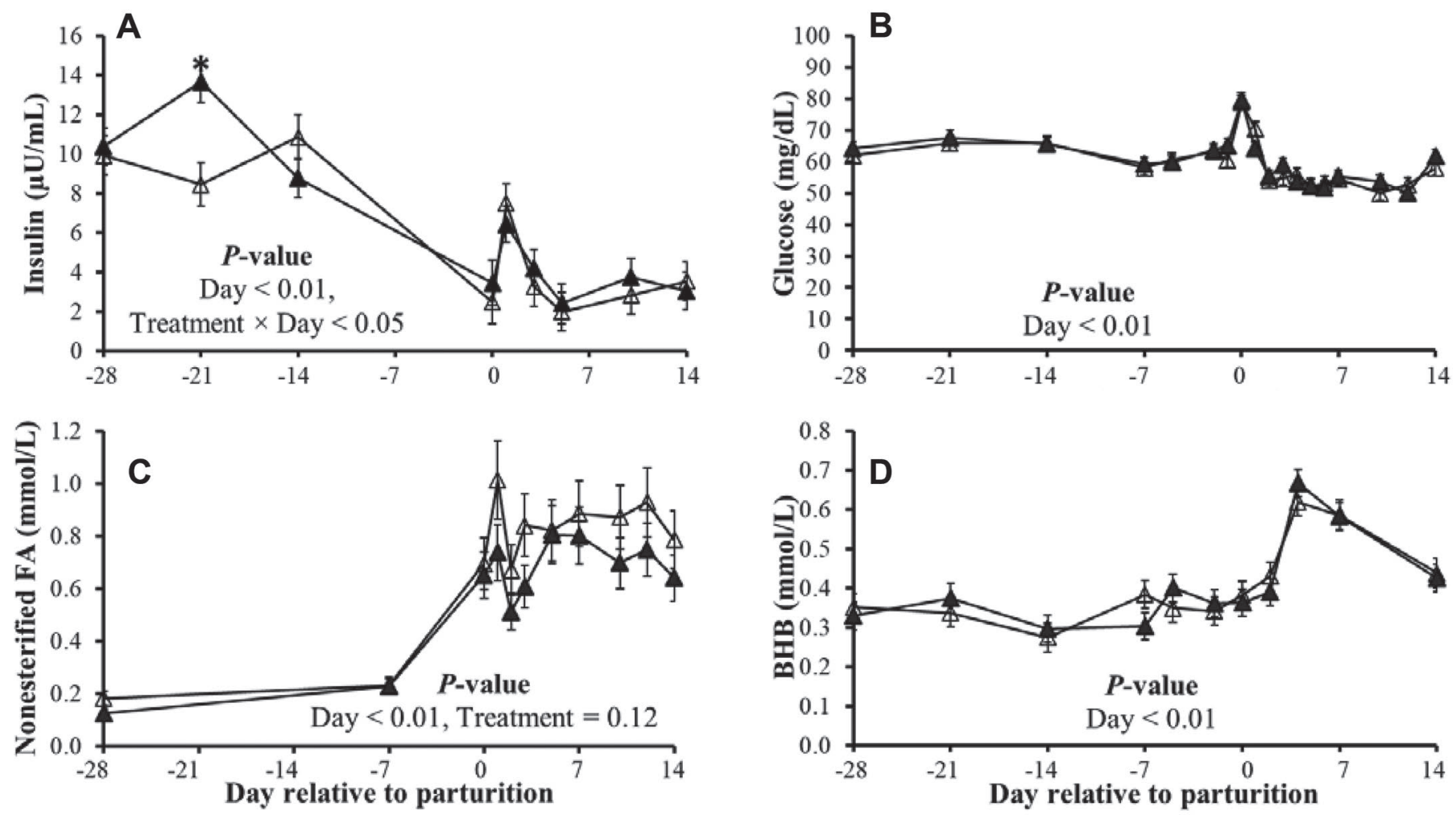

Figure 2. Plasma concentrations of (A) insulin, (B) glucose, (C) nonesterified fatty acids (FA), and (D) BHB in dairy cows ad libitum fed corn silage-based diets containing adequate Met without (control; $\mathrm{n}=13$ ) or with methyl donor supplementation $($ MDS; $\mathrm{n}=14$ ) during the transition period. Dietary MDS contained $22 \mathrm{~g} / \mathrm{d}$ of Met, $10 \mathrm{~g} / \mathrm{d}$ of choline chloride, $3 \mathrm{~g} / \mathrm{d}$ of betaine, $96 \mathrm{mg} / \mathrm{d}$ of riboflavin, and $1.4 \mathrm{mg} / \mathrm{d}$ of vitamin B12 (MecoVit, Vetagro S.p.A., Reggio Emilia, Italy). Data are presented as LSM \pm SEM; ${ }^{*} P<0.05 ; \dagger P<0.15$. If treatment or treatment $\times$ day significance is not shown then, $P>0.15$. 
TAG and CE with milk yield and milk lactose yield and percentage (Supplemental Table S4, https://doi.org/10 .3168/jds.2018-14727).

\section{DISCUSSION}

The periparturient dairy cows are characterized by poor metabolic health, which is defined by elevations in plasma nonesterified FA, BHB, and liver lipid content. The use of encapsulated methyl donors to mitigate liver lipid accumulation in cows has received considerable attention in recent years as a means to improve metabolic health (Piepenbrink and Overton, 2003; Davidson et al., 2008; Grummer, 2008). However, the effects of co-supplementing Met, choline, and betaine during the peripartum have not been evaluated. Our results suggest that methyl donor co-supplementation holds the potential to reduce the progression of liver lipid accumulation in cows fed adequate metabolizable Met; however, we are cognizant that recent data suggests that a dietary Lys-to-Met ratio closer to 2.8:1 may be beneficial to elicit improvements in milk production and DMI (Osorio et al., 2013), which were not observed in the present study.

Limited data describe the bioavailability of RP methyl donors during the periparturient period. We observed moderate increases in serum Met (17 and 35\% on $\mathrm{d} 10$ and 12 , respectively) with a reduction in the Lys-to-Met ratio. In comparison, Zhou et al. (2016a) reported a 55\% increase in plasma Met levels during the peripartal period in response to RP Met supplementation (6.9 vs. $9.2 \mathrm{~g} / \mathrm{d}$ of Met, prepartum vs. postpartum, respectively). As for NEAA, MDS tended to increase circulating Cys concentrations. Ordway et al. (2009) demonstrated that RP-Met was able to elevate plasma Met + Cys concentration during mid-lactation. The observed changes in blood Cys may be caused by the generation of methyl groups from supplemental Met to homocysteine followed by its metabolism to Cys (Girard et al., 2005). Regarding the bioavailability of methyl donors, the interpretation of our findings has limitations. First, we sampled at 3, 6, and $9 \mathrm{~h}$ postfeeding on d 10 and 12 postpartum for pooled serum AA analysis. Second, we did not compare dietary RP MDS with unprotected methyl donors infused abomasally. Thus, our results may not be an adequate representation of intestinally absorbed bioavailable Met. We also did not measure changes in circulating choline, choline-containing compounds, betaine, riboflavin, or vitamin $\mathrm{B}_{12}$. This is of potential concern because of recent reports that suggest limited portal flux of choline in response to RP choline supplementation $(\leq 25$ $\mathrm{g} / \mathrm{d}$ ) in late-lactation dairy cows (de Veth et al., 2016). Because of the commercial insurgence of methyl donor lipid encapsulates, adequate methyl donor bioavailability should be addressed in periparturient dairy cows. Although we recognize our limitations, MDS increased serum Met and improved metabolic health even in cows fed adequate metabolizable Met; therefore, these outcomes support intestinal absorption.

The observed dramatic decline in postpartum plasma insulin is a classical characteristic of the lipolytic dairy during early lactation (Bauman and Currie, 1980). In our study, MDS increased prepartum insulin in the absence of change in DMI. In support, Leiva et al. (2015)

\section{$\square$ Control $\square$ MDS}
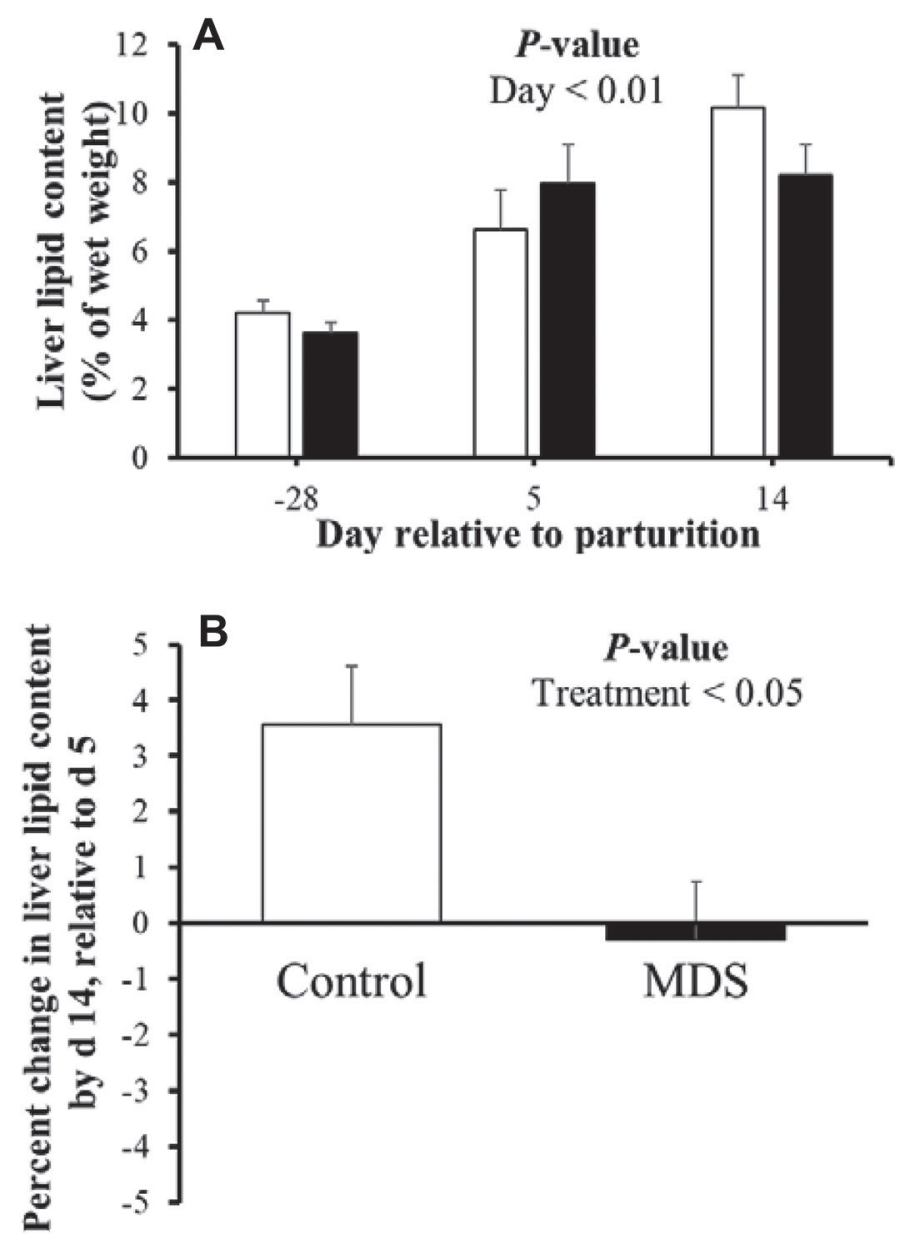

Figure 3. (A) Liver lipid content as a percent of wet weight or (B) percent change in liver lipid content from d 5 to 14 in dairy cows ad libitum fed corn silage-based diets containing adequate Met without (control; $\mathrm{n}=13$ ) or with methyl donor supplementation (MDS; $\mathrm{n}=$ 14) during the transition period. Dietary MDS contained $22 \mathrm{~g} / \mathrm{d}$ of Met, $10 \mathrm{~g} / \mathrm{d}$ of choline chloride, $3 \mathrm{~g} / \mathrm{d}$ of betaine, $96 \mathrm{mg} / \mathrm{d}$ of riboflavin, and $1.4 \mathrm{mg} / \mathrm{d}$ of vitamin $\mathrm{B}_{12}$ (MecoVit, Vetagro S.p.A., Reggio Emilia, Italy). Data are presented as LSM \pm SEM; ${ }^{*} P<0.05 ; \dagger P<$ 0.15 . If treatment, day, or treatment $\times$ day significance is not shown, then $P>0.15$. 
demonstrated that prepartum RP-choline supplementation (9 $\mathrm{g} / \mathrm{d}$ of choline) increased serum insulin concentrations. Elevations in circulating insulin would favor lipogenesis and suppress lipolysis. We did not observe a change in prepartum plasma nonesterified FA levels during MDS; however, our study cows were clinically healthy prepartum, as demonstrated by minimal plasma nonesterified FA $(<0.2 \mathrm{mmol} / \mathrm{L})$ and liver lipid content $(<4 \%)$. Therefore, the action of MDS-induced insulin to lower plasma nonesterified FA was likely minimal prepartum. Postpartum, MDS was able to consistently lower circulating FA without a change in DMI. For comparison, prepartum supplementation with choline (20 g/d) has been shown to significantly decrease circulating FA at calving (Pinotti et al., 2003); in contrast, others did not observe a FA response with RP choline (Piepenbrink and Overton, 2003; Guretzky et al., 2006; Zhou et al., 2016b). The observed tendency for lower plasma FA levels with MDS likely supported the reduction in total hepatic lipid deposition that was observed between d 5 and 14 of lactation, although ketogenesis was not influenced. Comparable to our results, Cooke et al. (2007) and Zom et al. (2011) detected lower liver total TAG concentrations when $\sim 15 \mathrm{~g} / \mathrm{d}$ of choline was supplemented to dairy cows peripartum. We recognize that cows that remained in the study were clinically healthy; prepartum health was not compromised and only moderate increases in circulating FA and liver content were observed postpartum. Therefore, the possibility exists that hepatic methyl donor supply was partially adequate. Further research will need to determine whether MDS improves metabolic health in cows at heightened risk for metabolic disease (e.g., postpartum plasma nonesterified $\mathrm{FA} \geq 1.0 \mathrm{mmol} / \mathrm{L}$ or $>12 \%$ lipids of liver as wet weight basis) or fed diets inadequate in metabolizable Met.

Plasma TAG and CE are major components of liverderived VLDL. Postpartum reductions in plasma TAG concentrations may be caused by limited hepatic VLDL export and enhanced clearance of circulating TAG by lipoprotein lipase in the mammary gland (Van den Top et al., 1996; Finucane et al., 2008). Although we observed dramatic reductions in postpartum plasma total TAG levels, the inability of MDS to modify total TAG or cholesterol concentrations is supported by others (Pinotti et al., 2003; Guretzky et al., 2006; Davidson et al., 2008), whereas RP-choline tended to lower serum total TAG concentrations prepartum (Guretzky et al., 2006). Although we did not observe a change in circulating total TAG with MDS, the possibility remains that MDS was able to improve hepatic TAG secretion, which was not evaluated in the present study.

Peripartal lipidomic changes in individual plasma TAG and CE generally reflected total TAG and CE as measured using colorimetry; however, we were able to distinguish unique time and treatment effects for specific TAG and CE. For instance, some TAG increased from d -28 to -7 prepartum (e.g., TAG 46:3 and 48:0), whereas others remained stable or decreased (e.g., TAG 54:0 or 58:5). Specific TAG containing $\leq 54$ carbons are enriched in medium or long-chain FA (e.g., myristic and palmitic acids). Although our analytical approach did not allow us to identify the FA moieties in each TAG or CE molecule, the difference in individual TAG

\section{$\triangle$ Control $\triangle$-MDS}
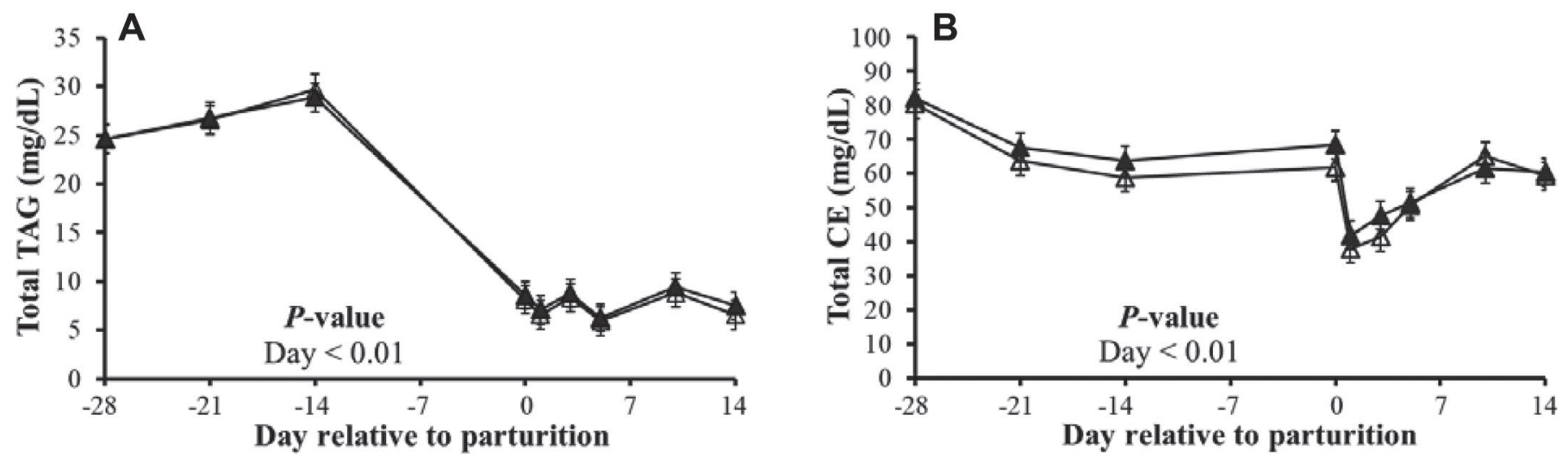

Figure 4. Plasma concentrations of (A) total triacylglycerol (TAG) and (B) total cholesteryl esters (CE) in dairy cows ad libitum fed corn silage-based diets containing adequate Met without (control; $\mathrm{n}=13$ ) or with methyl donor supplementation $($ MDS; $\mathrm{n}=14)$ during the transition period. Dietary MDS contained $22 \mathrm{~g} / \mathrm{d}$ of Met, $10 \mathrm{~g} / \mathrm{d}$ of choline chloride, $3 \mathrm{~g} / \mathrm{d}$ of betaine, $96 \mathrm{mg} / \mathrm{d}$ of riboflavin, and $1.4 \mathrm{mg} / \mathrm{d}$ of vitamin $\mathrm{B}_{12}$ (MecoVit, Vetagro S.p.A., Reggio Emilia, Italy). Data are presented as LSM \pm SEM; $* P<0.05 ; \dagger P<0.15$. For both panels, the $P$-values for treatment and treatment $\times$ day were greater than 0.15 
and $\mathrm{CE}$ responsiveness were likely due to peripartal fluctuations in circulating FA substrate supply during the peripartum (Gruffat et al., 1996; Rukkwamsuk et al., 2000; Contreras et al., 2010). Alternatively, periparturient modifications in the transcriptional expression of acyltransferases, which have variable fatty acyl-CoA specificities, may be the cause (Sgoutas et al., 1972; Takeuchi and Reue, 2009; Loor, 2010).

The collective lipidomic understanding of fatty liver disease in cattle and humans is in its infancy. Choles- teryl esters are packaged with TAG in VLDL; therefore, elevations in plasma CE may also reflect improved VLDL secretion. However, plasma CE may also be found within low-density lipoproteins, and $\mathrm{CE}$ found with low-density lipoproteins may not be liver-derived but, rather, derived from extra-hepatic cholesterol trafficking (Chang et al., 2009). It will be important to understand the role of CE in VLDL formation, especially with regard to the apparent competition between $\mathrm{CE}$ and TAG for the hydrophobic core (Davis et al., 1982).

\section{$\triangle$ Control $\triangle$ MDS}
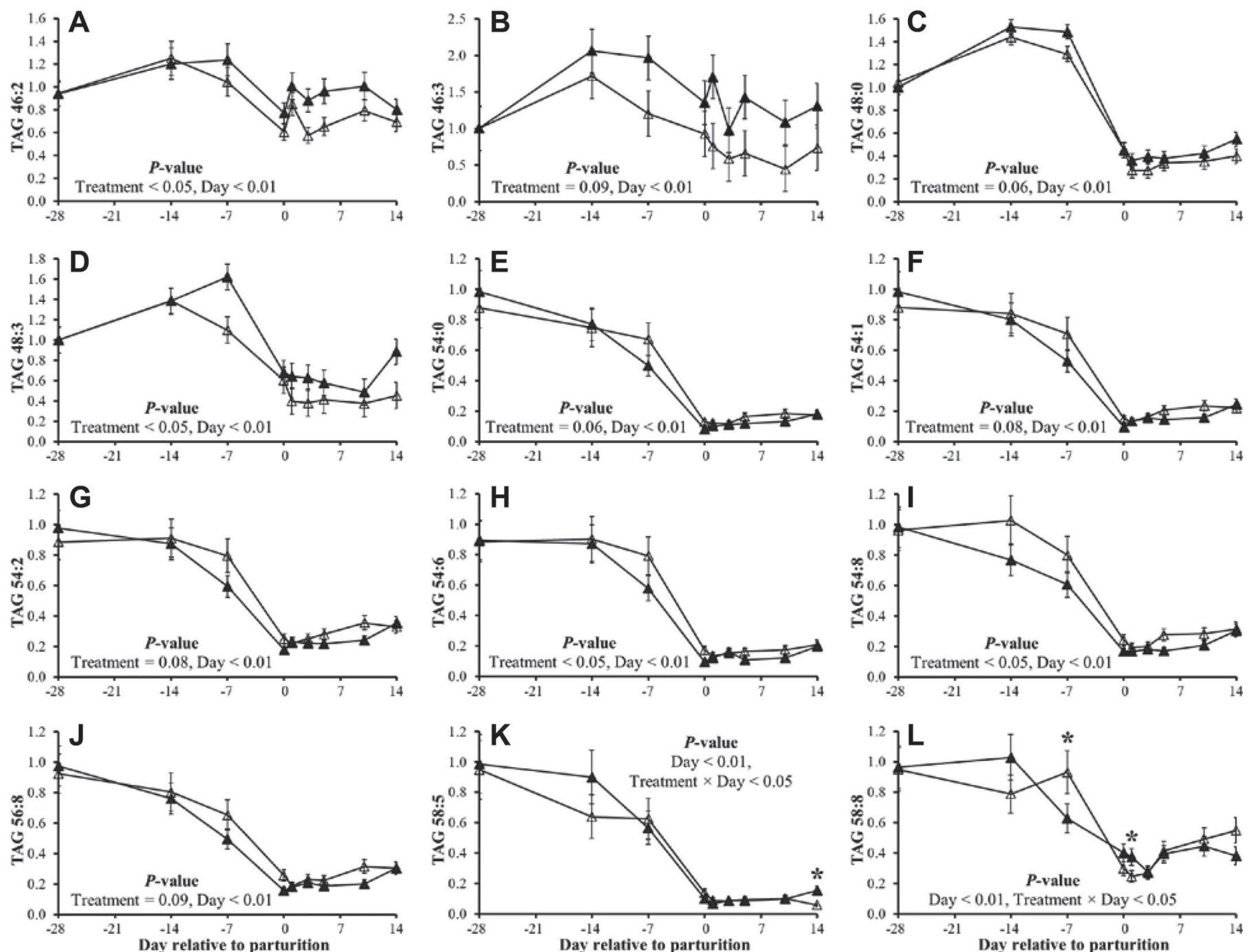

Figure 5. Plasma concentrations of (A) triacylglycerol (TAG) 46:2, (B) TAG 46:3, (C) TAG 48:0, (D) TAG 48:3, (E) TAG 54:0, (F) TAG 54:1, (G) TAG 54:2, (H) TAG 54:6, (I) TAG 54:8, (J) TAG 56:8, (K) TAG 58:5, and (L) TAG 58:8 in dairy cows ad libitum fed corn silage-based diets containing adequate Met without (control; $\mathrm{n}=13$ ) or with methyl donor supplementation (MDS; $\mathrm{n}=14$ ) during the transition period. Dietary MDS contained $22 \mathrm{~g} / \mathrm{d}$ of Met, $10 \mathrm{~g} / \mathrm{d}$ of choline chloride, $3 \mathrm{~g} / \mathrm{d}$ of betaine, $96 \mathrm{mg} / \mathrm{d}$ of riboflavin, and $1.4 \mathrm{mg} / \mathrm{d}$ of vitamin B $\mathrm{B}_{12}(\mathrm{MecoVit}$, Vetagro S.p.A., Reggio Emilia, Italy). The TAG data are denoted as fold-change relative to $\mathrm{d}-28$. Data are presented as LSM \pm SEM; ${ }^{*} P<$ $0.05 ; \dagger P<0.15$. If treatment, day, or treatment $\times$ day significance is not shown, then $P>0.15$. 
Although MDS increased CE 34:6, the contribution of this CE to VLDL neutral lipid export is likely minimal considering the fatty acid is an atypical very long chain FA.

The TAG represent the predominant VLDL neutral lipid, which is of greatest importance to alleviating fatty liver in cows. Recent work has demonstrated unique TAG profiles in obese humans with nonalcoholic fatty liver disease relative to nonobese individuals without the disease (Hyysalo et al., 2014). Although these early insights have value for humans, we refrained from drawing comparisons across species because of pronounced differences in hepatic and lipoprotein metabolism. Most notably, periparturient dairy cows develop fatty liver disease in parallel with inadequate VLDL secretion and elevations in mammary lipoprotein lipase activity (Van den Top et al., 2005). Our results are comparable to recent work by Imhasly et al. (2015), who used a similar approach to characterize changes in TAG during the peripartum; however, those authors did not determine which species were biomarkers for fatty liver in cows. Although we did not address this question ourselves, we did identify specific TAG that were responsive to dietary MDS. For example, MDS increased circulating TAG 46:2, 46:3, 48:0, 48:3, 58:8, and 58:5. This outcome may be due to improved hepatic PC synthesis and VLDL-TAG secretion. We also emphasized that lipolysis increases the supply of palmitic, oleic, and linoleic acids to the liver, which are re-esterified into TAG (Rukkwamsuk et al., 2000). Hepatic TAG 46:2, 46:3,
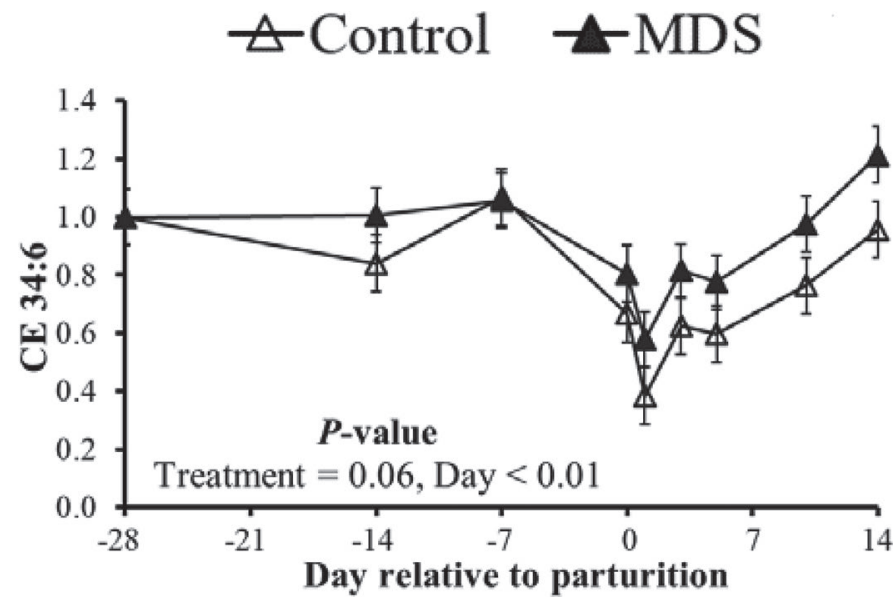

Figure 6. Plasma concentrations of cholesteryl ester (CE) 34:6 in dairy cows ad libitum fed corn silage-based diets containing adequate Met without (control; $\mathrm{n}=13$ ) or with methyl donor supplementation (MDS; $\mathrm{n}=14$ ) during the transition period. The CE data are denoted as fold-change relative to d -28 . Dietary MDS contained $22 \mathrm{~g} / \mathrm{d}$ of Met, $10 \mathrm{~g} / \mathrm{d}$ of choline chloride, $3 \mathrm{~g} / \mathrm{d}$ of betaine, $96 \mathrm{mg} / \mathrm{d}$ of riboflavin, and $1.4 \mathrm{mg} / \mathrm{d}$ of vitamin $\mathrm{B}_{12}$ (MecoVit, Vetagro S.p.A., Reggio Emilia, Italy). Data are presented as LSM \pm SEM; ${ }^{*} P<0.05 ; \dagger P<0.15$. The $P$-value for treatment $\times$ day is greater than 0.15 .
48:0, 48:3, and 58:5 likely contain these FA; therefore, MDS may amplify the ability of the liver to export lipolytic-derived FA. However, our reasoning does not explain why select TAG were lowered by MDS (e.g., TAG 54:8). It is clear that the nonuniform changes in the plasma TAG lipidome develop in response to MDS. These changes may be due to the ability of methyl donors to modulate DNA methylation of lipogenic genes, including fatty acid synthase, sterol regulatory element-binding protein, and acylglycerophosphate acyltransferase (Dahlhoff et al., 2014; Zeisel, 2017). Future research will need to optimize the ability of MDS to increase the hepatic secretion of all TAG, because lowering hepatic lipid content has the potential to improve gluconeogenesis and mitochondrial $\beta$-oxidation (Rukkwamsuk et al., 1999; Litherland et al., 2011).

\section{CONCLUSIONS}

Co-supplementation of RP Met, choline chloride, betaine, riboflavin, and vitamin $\mathrm{B}_{12}$ limited the progression of postpartum hepatic lipid deposition and modified the plasma TAG lipidome in periparturient Holstein dairy cows without modifications in DMI or milk production. These findings suggest that RP methyl donor co-supplementation holds the potential to improve hepatic health in early-lactation cows. Future research should determine which combinations of methyl donors maximize liver lipid disposal. Moreover, we should determine whether the ability of MDS to enhance plasma TAG 46:2, 46:3, 48:0, and 48:3 corresponds with enhanced hepatic secretion of these species, and whether these outcomes explain the reduction in hepatic lipid accumulation.

\section{ACKNOWLEDGMENTS}

We acknowledge the financial support provided by Vetagro S.p.A. (Reggio Emilia, Italy) and the West Virginia University Davis College of Agriculture, Natural Resources and Design (Morgantown, WV). We are grateful for the technical assistance from Eduardo Rico, Alice Matthews, and Zachary Phipps (West Virginia University, Morgantown). Moreover, we thank the laboratory of Norman Haughey (Johns Hopkins University, Baltimore, MD) for the mass spectrometry analysis. A special thanks to the Van Gilder family at DoVan Farms (Berlin, PA) for providing animal and facility resources.

\section{REFERENCES}

AOAC International. 2000. Official Methods of Analysis. 17th rev. ed. AOAC International, Arlington, VA. 
AOAC International. 2006. Official Methods of Analysis. 18th ed. AOAC International, Gaithersburg, MD.

Badawy, A. B., C. J. Morgan, and J. A. Turner. 2008. Application of the phenomenex EZ: faast ${ }^{\mathrm{TM}}$ amino acid analysis kit for rapid gaschromatographic determination of concentrations of plasma tryptophan and its brain uptake competitors. Amino Acids 34:587-596.

Batistel, F., J. Arroyo, A. Bellingeri, L. Wang, B. Saremi, C. Parys, E. Trevisi, F. Cardoso, and J. Loor. 2017. Ethyl-cellulose rumenprotected methionine enhances performance during the periparturient period and early lactation in Holstein dairy cows. J. Dairy Sci. 100:7455-7467.

Bauman, D. E., and W. B. Currie. 1980. Partitioning of nutrients during pregnancy and lactation: a review of mechanisms involving homeostasis and homeorhesis. J. Dairy Sci. 63:1514-1529.

Bligh, E. G., and W. J. Dyer. 1959. A rapid method of total lipid extraction and purification. Can. J. Biochem. Physiol. 37:911-917.

Bobe, G., V. R. Amin, D. C. Beitz, and J. W. Youngs. 2004a. Noninvasive diagnosis of fatty liver and degree of fatty liver in dairy cows by digital analyses of hepatic ultrasonograms. Accessed Mar. 3, 2018. https://lib.dr.iastate.edu/ans_air/vol650/iss1/64/.

Bobe, G., J. Young, and D. Beitz. 2004b. Invited review: Pathology, etiology, prevention, and treatment of fatty liver in dairy cows. J. Dairy Sci. 87:3105-3124.

Chang, T. Y., B. Li, C. C. Chang, and Y. Urano. 2009. Acyl-coenzyme A:cholesterol acyltransferases. Am. J. Physiol. Endocrinol. Metab. 297:E1-E9.

Contreras, G. A., N. O'boyle, T. Herdt, and L. Sordillo. 2010. Lipomobilization in periparturient dairy cows influences the composition of plasma nonesterified fatty acids and leukocyte phospholipid fatty acids. J. Dairy Sci. 93:2508-2516.

Cooke, R. F., N. S. Del Rio, D. Caraviello, S. Bertics, M. Ramos, and R. Grummer. 2007. Supplemental choline for prevention and alleviation of fatty liver in dairy cattle. J. Dairy Sci. 90:2413-2418.

Dahlhoff, C., S. Worsch, M. Sailer, B. A. Hummel, J. Fiamoncini, K. Uebel, R. Obeid, C. Scherling, J. Geisel, and B. L. Bader. 2014. Methyl-donor supplementation in obese mice prevents the progression of NAFLD, activates AMPK and decreases acyl-carnitine levels. Mol. Metab. 3:565-580.

Davidson, S., B. Hopkins, J. Odle, C. Brownie, V. Fellner, and L. Whitlow. 2008. Supplementing limited methionine diets with rumen-protected methionine, betaine, and choline in early lactation Holstein cows. J. Dairy Sci. 91:1552-1559.

Davis, R. A., M. M. McNeal, and R. Moses. 1982. Intrahepatic assembly of very low density lipoprotein. competition by cholesterol esters for the hydrophobic core. J. Biol. Chem. 257:2634-2640.

de Veth, M. J., V. Artegoitia, S. Campagna, H. Lapierre, F. Harte, and C. Girard. 2016. Choline absorption and evaluation of bioavailability markers when supplementing choline to lactating dairy cows. J. Dairy Sci. 99:9732-9744.

Emery, R. S., J. S. Liesman, and T. H. Herdt. 1992. Metabolism of long chain fatty acids by ruminant liver. J. Nutr. 122:832-837.

Finucane, K. A., T. B. McFadden, J. P. Bond, J. J. Kennelly, and F. Q. Zhao. 2008. Onset of lactation in the bovine mammary gland: Gene expression profiling indicates a strong inhibition of gene expression in cell proliferation. Funct. Integr. Genomics 8:251-264.

Girard, C. L., H. Lapierre, J. Matte, and G. Lobley. 2005. Effects of dietary supplements of folic acid and rumen-protected methionine on lactational performance and folate metabolism of dairy cows. J. Dairy Sci. 88:660-670.

Gruffat, D., D. Durand, B. Graulet, and D. Bauchart. 1996. Regulation of VLDL synthesis and secretion in the liver. Reprod. Nutr. Dev. 36:375-389.

Grummer, R. R. 2008. Nutritional and management strategies for the prevention of fatty liver in dairy cattle. Vet. J. 176:10-20.

Guretzky, N. A., D. Carlson, J. Garrett, and J. Drackley. 2006. Lipid metabolite profiles and milk production for Holstein and Jersey cows fed rumen-protected choline during the periparturient period. J. Dairy Sci. 89:188-200.

Hall, M. B. 2009. Determination of starch, including maltooligosaccharides, in animal feeds: comparison of methods and a method recommended for AOAC collaborative study. J. AOAC Int. 92:42-49.
Huber, J. T., R. Emery, W. Bergen, J. Liesman, L. Kung, K. King, R. Gardner, and M. Checketts. 1984. Influences of methionine hydroxy analog on milk and milk fat production, blood serum lipids, and plasma amino acids. J. Dairy Sci. 67:2525-2531.

Hyysalo, J., P. Gopalacharyulu, H. Bian, T. Hyötyläinen, M. Leivonen, N. Jaser, A. Juuti, M. J. Honka, P. Nuutila, and V. M. Olkkonen. 2014. Circulating triacylglycerol signatures in nonalcoholic fatty liver disease associated with the $1148 \mathrm{M}$ variant in PNPLA3 and with obesity. Diabetes 63:312-322.

Imhasly, S., C. Bieli, H. Naegeli, L. Nyström, M. Ruetten, and C. Gerspach. 2015. Blood plasma lipidome profile of dairy cows during the transition period. BMC Vet. Res. 11:252.

Jorritsma, R., H. Jorritsma, Y. Schukken, P. Bartlett, T. Wensing, and G. Wentink. 2001. Prevalence and indicators of post partum fatty infiltration of the liver in nine commercial dairy herds in the Netherlands. Livest. Prod. Sci. 68:53-60.

Leiva, T., R. Cooke, A. Brandao, R. Marques, and J. Vasconcelos. 2015. Effects of rumen-protected choline supplementation on metabolic and performance responses of transition dairy cows. J. Anim. Sci. 93:1896-1904.

Litherland, N. B., H. Dann, and J. Drackley. 2011. Prepartum nutrient intake alters palmitate metabolism by liver slices from peripartal dairy cows. J. Dairy Sci. 94:1928-1940.

Loor, J. J. 2010. Genomics of metabolic adaptations in the peripartal cow. Animal 4:1110-1139.

Nam, M., M. S. Choi, S. Jung, Y. Jung, J. Y. Choi, and G. S. Hwang. 2015. Lipidomic profiling of liver tissue from obesity-prone and obesity-resistant mice fed a high fat diet. Sci. Rep. 5:16984.

Ordway, R. S., S. Boucher, N. Whitehouse, C. Schwab, and B. Sloan. 2009. Effects of providing two forms of supplemental methionine to periparturient Holstein dairy cows on feed intake and lactational performance. J. Dairy Sci. 92:5154-5166.

Osorio, J. S., P. Ji, J. Drackley, D. Luchini, and J. Loor. 2013. Supplemental Smartamine M or MetaSmart during the transition period benefits postpartal cow performance and blood neutrophil function. J. Dairy Sci. 96:6248-6263.

Piepenbrink, M. S., and T. Overton. 2003. Liver metabolism and production of cows fed increasing amounts of rumen-protected choline during the periparturient period. J. Dairy Sci. 86:1722-1733.

Pinotti, L., A. Baldi, and V. Dell'Orto. 2002. Comparative mammalian choline metabolism with emphasis on the high-yielding dairy cow. Nutr. Res. Rev. 15:315-332.

Pinotti, L., A. Baldi, I. Politis, R. Rebucci, L. Sangalli, and V. Dell'Orto. 2003. Rumen-protected choline administration to transition cows: Effects on milk production and vitamin E status. J. Vet. Med. A Physiol. Pathol. Clin. Med. 50:18-21.

Preynat, A., H. Lapierre, M. C. Thivierge, M. F. Palin, N. Cardinault, J. J. Matte, A. Desrochers, and C. L. Girard. 2010. Effects of supplementary folic acid and vitamin B 12 on hepatic metabolism of dairy cows according to methionine supply. J. Dairy Sci. 93:2130-2142.

Puri, P., M. M. Wiest, O. Cheung, F. Mirshahi, C. Sargeant, H. K. Min, M. J. Contos, R. K. Sterling, M. Fuchs, and H. Zhou. 2009. The plasma lipidomic signature of nonalcoholic steatohepatitis. Hepatology 50:1827-1838.

Rukkwamsuk, T., M. Geelen, T. Kruip, and T. Wensing. 2000. Interrelation of fatty acid composition in adipose tissue, serum, and liver of dairy cows during the development of fatty liver postpartum. J. Dairy Sci. 83:52-59.

Rukkwamsuk, T., T. Wensing, and M. J. Geelen. 1999. Effect of fatty liver on hepatic gluconeogenesis in periparturient dairy cows. J. Dairy Sci. 82:500-505.

Sgoutas, D. S., M. Leight, and R. King. 1972. Fatty acid specificity of plasma phosphatidylcholine: cholesterol acyltransferase. Biochemistry 11:293-296.

Starke, A., A. Haudum, R. Busche, M. Beyerbach, S. Dänicke, and J. Rehage. 2010. Technical note: Analysis of total lipid and triacylglycerol content in small liver biopsy samples in cattle. J. Anim. Sci. 88:2741-2750. 
Takeuchi, K., and K. Reue. 2009. Biochemistry, physiology, and genetics of GPAT, AGPAT, and lipin enzymes in triglyceride synthesis. Am. J. Physiol. Endocrinol. Metab. 296:E1195-E1209.

Van den Top, A. M., A. Marc, M. J. Geelen, T. Wensing, and G. H. Wentink. 1996. Higher postpartum hepatic triacylgylcerol concentrations in dairy cows with free rather than restricted access to feed during the dry period are associated with lower activities of hepatic glycerolphosphate acyltransferase. J. Nutr. 126:76-85.

Van den Top, A. M., A. Van Tol, H. Jansen, M. J. Geelen, and A. C. Beynen. 2005. Fatty liver in dairy cows post partum is associated with decreased concentration of plasma triacylglycerols and decreased activity of lipoprotein lipase in adipocytes. J. Dairy Res. 72:129-137.

Van Soest, P. J., J. Robertson, and B. Lewis. 1991. Methods for dietary fiber, neutral detergent fiber, and nonstarch polysaccharides in relation to animal nutrition. J. Dairy Sci. 74:3583-3597.

Vermeulen, P. S., S. Lingrell, Z. Yao, and D. Vance. 1997. Phosphatidylcholine biosynthesis is required for secretion of truncated apolipoprotein Bs from McArdle RH7777 cells only when a neutral lipid core is formed. J. Lipid Res. 38:447-458.

Wildman, E., G. Jones, P. Wagner, R. Boman, H. Troutt, and T. Lesch. 1982. A dairy cow body condition scoring system and its relationship to selected production characteristics. J. Dairy Sci. 65:495-501.

Yao, Z. M., and D. E. Vance. 1988. The active synthesis of phosphatidylcholine is required for very low density lipoprotein secretion from rat hepatocytes. J. Biol. Chem. 263:2998-3004.
Zahra, L. C., T. Duffield, K. Leslie, T. Overton, D. Putnam, and S. LeBlanc. 2006. Effects of rumen-protected choline and monensin on milk production and metabolism of periparturient dairy cows. J. Dairy Sci. 89:4808-4818.

Zeisel, S. 2017. Choline, other methyl-donors and epigenetics. Nutrients 9:445.

Zenobi, M. G., R. Gardinal, J. Zuniga, A. Dias, C. Nelson, J. Driver, B. Barton, J. Santos, and C. Staples. 2018. Effects of supplementation with ruminally protected choline on performance of multiparous Holstein cows did not depend upon prepartum caloric intake. J. Dairy Sci. 101:1088-1110.

Zhou, Z., M. Vailati-Riboni, D. N. Luchini, and J. J. Loor. 2016a. Methionine and choline supply during the periparturient period alter plasma amino acid and one-carbon metabolism profiles to various extents: potential role in hepatic metabolism and antioxidant status. Nutrients 9:10.

Zhou, Z., M. Vailati-Riboni, E. Trevisi, J. Drackley, D. Luchini, and J. Loor. 2016b. Better postpartal performance in dairy cows supplemented with rumen-protected methionine compared with choline during the peripartal period. J. Dairy Sci. 99:8716-8732.

Zom, R. L., J. Van Baal, R. Goselink, J. Bakker, M. De Veth, and A. Van Vuuren. 2011. Effect of rumen-protected choline on performance, blood metabolites, and hepatic triacylglycerols of periparturient dairy cattle. J. Dairy Sci. 94:4016-4027. 